\title{
Hypothesis
}

\section{CARVEDILOL AS A POTENTIAL ADDITION TO THE COVID-19 THERAPEUTIC ARSENAL}

\author{
NAKHLE AYOUB MD. ${ }^{1,2}$ \\ ${ }^{1}$ Hôtel Dieu de France Hospital, Dermatology Department, Beirut, Lebanon, ${ }^{2}$ Holy Spirit University, Kaslik, Lebanon \\ Email: nakhleayoub@yahoo.com
}

Received: 28 Apr 2020, Revised and Accepted: 09 May 2020

\begin{abstract}
No single therapeutic agent has been recognized so far as the ultimate treatment for COVID-19 and many treatment strategies rely on associating different medications with proven or hypothetical anti-viral effects. Carvedilol is a third-generation beta-blocker displaying potential inhibitory properties on several key enzymatic processes and pathways involved in SARS-CoV-2 or other coronaviruses replication, in addition to the modulatory effect on several inflammatory messengers of COVID-19. These data could provide a reasonable hypothetical background for further investigating specific anti-SARS-CoV-2 effects and could pave the way for further clinical verification.
\end{abstract}

Keywords: Carvedilol, SARS-CoV-2, COVID-19

(c) 2020 The Authors. Published by Innovare Academic Sciences Pvt Ltd. This is an open access article under the CC BY license (http://creativecommons.org/licenses/by/4.0/) DOI: http://dx.doi.org/10.22159/ijpps.2020v12i6.38057. Journal homepage: https://innovareacademics.in/journals/index.php/ijpps.

Speedy peer review was done as the subject of the manuscript was related with pandemic

\section{INTRODUCTION}

As global efforts are deployed to contain the novel coronavirus disease 2019 (COVID-19) pandemic, several candidate treatments are being used in clinical practice and/or tested in ongoing trials. Despite promising results, no single therapeutic agent has been identified as the ultimate treatment for severe acute respiratory syndrome coronavirus 2 (SARS-COV-2), and many protocols rely on associating different molecules with proven or putative anti-viral effects. Carvedilol is a non-specific $ß$-blocker indicated in congestive heart failure and hypertension, but additional anti-inflammatory and anti-oxidant properties and involvement in the regulation of various intracellular signaling pathways draw a distinctive pleiotropic profile for this cardiovascular agent [1-4]. While bronchoconstriction in asthmatic patients is a known side-effect of carvedilol, its specific impact on the intracellular pathways of the respiratory epithelial cell has not been fully addressed yet. Emerging data, however, shed light on new properties of carvedilol, allowing reasonable assumptions that, by acting on several cellular levels of SARS-CoV-2 and other similar coronaviruses, this agent could help control or mitigate the current COVID-19 pandemic.

\section{Hypothesis}

SARS-CoV-2 penetrates the cell after binding to angiotensin converting enzyme 2 (ACE 2), where the host cell proteases cleave certain viral proteins at low $\mathrm{pH}$, resulting in the release of the viral genome into the cytoplasm. Viral main proteases, including 3chymotrypsin-like protease (3CLpro), along with diverted intracellular enzymatic processes and pathways, including replicasetranscriptase complex, mitogen-activated protein kinases (MAP-K) and ribososome machinery, are subsequently used in favour of the viral RNA transcription and protein synthesis. Following replication and assembly, the newly formed viral particles are transported to the cell surface in vesicles through the Golgi system before being released by exocytosis and infecting new host cells [5].

Carvedilol has been shown to downregulate angiotensin converting enzyme expression [6], which shares substantial structural similarities with ACE 2. Although the specific effect of carvedilol on ACE2 is not well documented, we hypothesize that this agent could play an inhibitory role on several intracellular key levels of SARS-CoV-2 cycle. It could be indeed limiting coronavirus synthesis by increasing lysosomal pH [7]. By reducing p38 MAP-K activation, a ubiquitous conserved enzyme of eukaryote cells involved in promoting SARSCoV-2 intracellular synthesis, carvedilol may be additionally targeting the viral replication $[2,8,9]$. Moreover, carvedilol increases nitric oxide synthase activity and subsequently, nitric oxide levels, a molecule proven to inhibit the SARS-coronavirus replication cycle [10, 11]. Furthermore, carvedilol was identified as a potential inhibitor of 3-CLpro, the main SARS-CoV-2 protease, in a computational virtual three-dimensional molecular docking method, which retained few candidates out of the large ZINC U. S. Food and Drug Administrationapproved drug database [12].

In addition to the aforementioned mechanisms, recently identified beta $_{1}$-adrenergic receptors (ß1AR) of the Golgi apparatus, intervening in viral transportation and exocytosis of newly formed viral particles, pave the way for investigating additional unsuspected properties of beta-blockers in this setting [13]. $ß_{1} A R$ stimulation, indeed, increases the production of cyclic adenosyl monophosphate (cAMP), a positive modulator of the exocytic pathway and, inversely, their inhibition correlates with decreased concentrations of cAMP and retarted Golgi exocytic viral trafficking $[14,15]$. It can be fairly assumed that, by blocking these $\beta_{1} A R$, the cell-permeant agent carvedilol would reduce intercellular infectivity and viral propagation [13].

On another level, interleukin-6 (IL-6) holds a pivotal role in the inflammatory cascade of the severe and fatal cases of Covid-19 infections and high levels of IL-6 seem to represent a predictive factor of respiratory failure [16, 17]. Angiotensin II (AgII) as well seems to correlate with viral load and degree of lung injury [18]. Nuclear factor kappa-light-chain-enhancer of activated B cells (NF$\mathrm{kB}$ ) is another identified key player in the inflammatory signaling pathway of SARS-CoV infection and Covid-19 [19]. Inhibition of NF$\mathrm{KB}$ has been associated with reduced inflammation and increased survival in mice infected with SARS-CoV [17]. By down regulating IL6, AgII and NF-kB, carvedilol could be improving the outcome of patients with Covid-19 [4, 20, 21].

Finally, cyclodextrins are enabling excipients, used in the pharmaceutical industry to enhance drug bioavailability. With additional cholesterol sequestering properties, these cyclic oligisaccharides cause lipid raft disruption and structural deformation of the viral envelope and cholesterol depletion of host cell membranes, hampering thereby fusion of the viral envelope with the cell membrane $[22,24]$. Cyclodextrins have proven to reduce coronavirus infectivity and the development of cyclodextrinbased delivery systems for carvedilol could provide this medication with additional anti-viral effects $[25,26]$.

The hypothesis that carvedilol exerts an anti-viral effect and a protective role in COVID-19 could be tested at several levels. The 
possible inhibitory effect of carvedilol on viral replication and high titers could be studied in one or several cell lines of animal (VerohSLAM, Vero E6†, Vero-CCL81, RK13) or human (Hep G2, HuH-7†, HAE) origin that support the SARS-CoV-2 replication [27]. Reduction in viral RNA titers with the addition of carvedilol could be first experimental evidence supporting an anti-viral activity in vitro. Case-control or retrospective cohort studies, comparing clinical outcomes and biological markers of patients taking carvedilol with the outcomes and markers in control groups, could serve as an epidemiological assessment of a possible protective role for this agent. At last, since carvedilol is a relatively safe medication with rare contraindications, positive results of an open-labeled prospective trial of this agent in patients having moderate to severe COVID-19 could pave the way for further randomized controlled trials.

\section{CONCLUSION}

Since the non-selective beta-blocker carvedilol potentially acts on several key levels of SARS-CoV-2 infection, including intracellular replication and exocytosis, in addition to modulating IL-6, AgII and NF-kB levels, we hypothesize that this commonly used antihypertensive agent might be a valuable addition to the COVID-19 therapeutic armamentarium.

\section{OVERVIEW}

While the anti-oxidant and the anti-inflammatory properties and the protective effect of carvedilol in the setting of experimental viral infections are highlighted in several publications, possible specific anti-viral effects remain unaddressed. This paper provides a reasonable hypothetical background for investigating specific antiSARS-CoV-2 effects in vitro. Case-control or retrospective cohort studies could further help assess a possible protective role for this agent. Since carvedilol is a relatively safe medication with rare contraindications, positive results could pave the way for openlabeled prospective studies and randomized controlled trials.

\section{ABBREVIATIONS}

SARS-CoV: severe acute respiratory syndrome coronavirus, SARSCOV-2: severe acute respiratory syndrome coronavirus, COVID-19: coronavirus disease 2019, ACE: angiotensin-converting enzyme, MAP-K: mitogen-activated protein kinases, IL-6: interleukin-6, Ag2: angiotensin 2, NF-kB: nuclear factor kappa-light-chain-enhancer of activated B cells

\section{ACKNOWLEDGMENT}

None

\section{FUNDING}

Nil

\section{AUTHORS CONTRIBUTIONS}

All authors have equal contributions.

\section{CONFLICT OF INTERESTS}

Declared none

\section{REFERENCES}

1. Ma Z, Liu X, Zhang Q, Yu Z, Gao D. Carvedilol suppresses malignant proliferation of mammary epithelial cells through inhibition of the ROS-mediated PI3K/AKT signaling pathway. Oncol Rep 2019;41:811-8.

2. Liu B, Liu YJ. Carvedilol promotes retinal ganglion cell survival following optic nerve injury via ASK1-p38 MAPK pathway. CNS Neurol Disord: Drug Targets 2019;18:695-704.

3. Zawadzka K, Nowak M, Piwonski I, Lisowska K. The synergy of ciprofloxacin and carvedilol against staphylococcus aureusprospects of a new treatment strategy? Molecules 2019;24:4104.

4. Kurum T, Tatli E, Yuksel M. Effects of carvedilol on plasma levels of pro-inflammatory cytokines in patients with ischemic and nonischemic dilated cardiomyopathy. Cardiovasc Dis 2007;34:52-9.

5. Devaux CA, Rolain JM, Colson P, Raoult D. New insights on the anti-viral effects of chloroquine against coronavirus: what to expect for COVID-19? Int J Antimicrob Agents 2020;105938. http://doi:10.1016/j.ijantimicag.2020.105938.

6. Saijonmaa O, Nyman T, Fyhrquist F. Carvedilol inhibits basal and stimulated ACE production in human endothelial cells. J Cardiovasc Pharmacol 2004;43:616-21.

7. Meng D, Li Z, Wang G, Ling L, Wu Y, Zhang C. Carvedilol attenuates liver fibrosis by suppressing autophagy and promoting apoptosis in hepatic stellate cells. Biomed Pharmacother 2018;108:1617-27.

8. Banerjee S, Narayanan K, Mizutani T, Makino S. Murine coronavirus replication-induced p38 mitogen-activated protein kinase activation promotes interleukin- 6 production and virus replication in cultured cells. J Virol 2002;76:5937-48.

9. Park J, Ha H, Kim MS, Ahn HJ, Huh KH, Kim YS. Carvedilol inhibits platelet-derived growth factor-induced extracellular matrix synthesis by inhibiting cellular reactive oxygen species and mitogen-activated protein kinase activation. J Heart Lung Transplant 2006;25:683-9.

10. Kalinowski L, Dobrucki LW, Szczepanska Konkel M, Jankowski $\mathrm{M}$, Martyniec L, Angielski S, et al. Third-generation betablockers stimulate nitric oxide release from endothelial cells through ATP efflux: a novel mechanism for antihypertensive action. Circulation 2003;107:2747-52.

11. Akerstrom S, Mousavi Jazi M, Klingstrom J, Leijon M, Lundkvist A, Mirazimi A. Nitric oxide inhibits the replication cycle of severe acute respiratory syndrome coronavirus. J Virol 2005;79:1966-9.

12. Wu C, Liu Y, Yang Y, Zhang P, Zhong W, Wang Y, et al. Analysis of therapeutic targets for SARS-CoV-2 and discovery of potential drugs by computational methods. Acta Pharma Sin B 2020. https://doi.org/10.1016/j.apsb.2020.02.008

13. Nash CA, Wei W, Irannejad R, Smrcka AV. Golgi localized $\beta 1$ adrenergic receptors stimulate Golgi PI4P hydrolysis by PLC $\varepsilon$ to regulate cardiac hypertrophy. Elife 2019;8:e48167. https://doi:10.7554/eLife.48167

14. Yang Z, Kirton HM, MacDougall DA, Boyle JP, Deuchars J, Frater $\mathrm{B}$, et al. The Golgi apparatus is a functionally distinct $\mathrm{Ca} 2+$ store regulated by the PKA and Epac branches of the $\beta 1$-adrenergic signaling pathway. Sci Signal 2015;8:ra101.

15. Brignoni M, Pignataro OP, Rodriguez ML, Alvarez A, Vega Salas DE, Rodriguez-Boulan E, et al. Cyclic AMP modulates the rate of 'constitutive' exocytosis of apical membrane proteins in MadinDarby canine kidney cells. J Cell Sci 1995;108:1931-43.

16. Xiaohua C, Binghong Z, Yueming Q, Yurou C, Jie X, Yong F, et al. Detectable serum SARS-CoV-2 viral load (RNAaemia) is closely associated with drastically elevated interleukin 6 (IL-6) level in critically ill COVID-19 patients. medRxiv 2020. https://doi.org/10.1101/2020.02.29.20029520

17. Herold T, Jurinovic V, Arnreich C, Hellmuth JC, Von BergweltBaildon M, Klein M, et al. Level of IL-6 predicts respiratory failure in hospitalized symptomatic COVID-19 patients. medRxiv 2020. https://doi.org/10.1101/2020.04.01.20047381

18. Liu Y, Yang Y, Zhang C, Huang F, Wang F, Yuan J, et al. Clinical and biochemical indexes from 2019-nCoV infected patients linked to viral loads and lung injury. Sci Chin Life Sci 2020;63:364-74.

19. DeDiego ML, Nieto Torres JL, Regla Nava JA, Jimenez Guardeno JM,

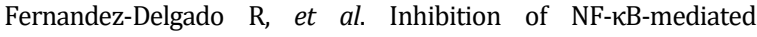
inflammation in severe acute respiratory syndrome coronavirusinfected mice increases survival. J Virol 2014;88:913-24.

20. Yang SP, Ho LJ, Lin YL, Cheng SM, Tsao TP, Chang DM, Hsu YL, et al. Carvedilol, a new antioxidative beta-blocker, blocks in vitro human peripheral blood $\mathrm{T}$ cell activation by downregulating NFkappa B activity. Cardiovasc Res 2003;59:776-87.

21. Blumenfeld JD, Sealey JE, Mann SJ, Bragat A, Marion R, Pecker $\mathrm{MS}$, et al. Beta-adrenergic receptor blockade as a therapeutic approach for suppressing the renin-angiotensin-aldosterone system in normotensive and hypertensive subjects. Am J Hypertens 1999;12:451-9. 
22. Baglivo M, Baronio $M$, Natalini G, Beccari T, Chiurazzi P, Fulcheri E, et al. Natural small molecules as inhibitors of coronavirus lipid-dependent attachment to host cells: a possible strategy for reducing SARS-COV-2 infectivity? Acta Biomed 2020;91:161-4.

23. Pratelli A, Colao V. Role of the lipid rafts in the life cycle of canine coronavirus. J Gen Virol 2015;96:331-7.

24. Glende J, Schwegmann Wessels C, Al-Falah M, Pfefferle S, Qu X, Deng $\mathrm{H}$, et al. Importance of cholesterol-rich membrane microdomains in the interaction of the S protein of SARS- coronavirus with the cellular receptor angiotensin-converting enzyme 2. Virology 2008;381:215-21.

25. Wen $X$, Tan F, Jing Z, Liu Z. Preparation and study the $1: 2$ inclusion complex of carvedilol with beta-cyclodextrin. J Pharm Biomed Anal 2004;34:517-23.

26. CK Oh Assignee, Smith Kline Beecham. Novel formulations of carvedilol. Patent No: W003028649; 2003.

27. Caly L, Druce JD, Catton MG, Jans DA, Wagstaff KM. The FDAapproved drug ivermectin inhibits the replication of SARS-CoV2 in vitro. Anti-viral Res 2020. https://doi.org/10.1016/ j.antiviral.2020.104787. 